\title{
His bundle recordings in paroxysmal atrioventricular block produced by carotid sinus massage
}

\author{
Agustin Castellanos, Ruey J. Sung, Damiao Cunha, and Robert J. Myerburg \\ From the Division of Cardiology, Department of Medicine, University of Miami School of Medicine and the \\ Medical Service, Veterans Administration Hospital, Miami, Florida, U.S.A.
}

Electrograms from the bundle of His were recorded in two patients with acute myocardial infarction during paroxysmal atrioventricular block induced by carotid sinus massage. From the viewpoint of the surface electrocardiogram this arrhythmia was considered as a form of Type II (Mobitz) klo:k, the onset of which was related to a decrease in atrial rate.

In the first patient, the conduction disturbance appeared at the $A H$, and in the second patient at the $H V$, level. Paroxysmal atrioventricular block could be explained by assuming the existence of: (a) vagal effects at the atrioventricular node or upper His bundle (Case I) and at 'lower' His bundle (Case 2); or (b) phase 4 block related to diastolic depolarization in 'upper' (Case I) and 'lower' (Case 2) parts of the His bundle; or (c) vagal effects at the atrioventricular node (Case I) and phase 4 block due to diastolic depolarization within the bundle of His (Case 2).

Several recent publications have discussed the electrocardiographic characteristics of a conduction disturbance which in 1933 was classified as paroxysmal atrioventricular block (Rosenbaum et al., 1973; Jensen et al., 1973; Testoni, Montemurro, and Tommaselli, 1973; Sachs and Traynor, 1933; Slama et al., 1969; Coumel et al., 1971). The latter was considered to have been present when normal or practically normal atrioventricular conduction was suddenly and unexpectedly followed by total interruption of AV conduction (Rosenbaum et al., 1973). Without further qualification, this description applies to Type II Mobitz AV block (Mobitz, 1924).

However, Rosenbaum and co-workers consider that there are several 'varieties' of paroxysmal atrioventricular block. These authors as well as Testoni et al. (1973) and Coumel et al. (197I) placed special emphasis on a form of block which was initiated by a slowing of the atrial rate. The purpose of this report is to present His bundle electrograms in two patients with a similar type of paroxysmal atrioventricular block and to discuss its possible genesis.

\section{Case I}

\section{Case reports}

Fig. I was obtained from a 45-year-old woman, with a 20-year history of recurrent tachyarrhythmias, who was Received ro December 1973. admitted because of an acute anteroseptal myocardial infarction. A pacemaker was introduced on the fifth day after infarction when she developed drugresistant sinus bradycardia. The latter alternated with paroxysms of supraventricular tachycardia. During sinus rhythm, the PR intervals and QRS complexes measured $140 \mathrm{msec}$ and $80 \mathrm{msec}$, respectively (Fig. I).

His bundle electrograms were recorded on the tenth post-infarction day, with the purpose of evaluating the arrhythmia and optimal drug therapy (Fig. 2). The conducting intervals measured from the first two (sinus) beats had the following values, in msec (figures in parentheses indicate normal ranges in our laboratory (Castillo and Castellanos, I97I)): PA:40 (20-40); $\mathrm{AH}: 50$ (50-120); and HV: 50 (35-55).

Fig. 2 and 3 are continuous tracings showing the onset and termination of carotid sinus massage (arrows pointing downward). In Fig. 2 the first non-conducted (fifth) $P$ wave was preceded by AV intervals of constant value. On the other hand, the PP intervals showed a gradual prolongation: $520 \mathrm{msec}, 540 \mathrm{msec}$, and 700 msec. Hence, the fifth $P$ wave was blocked when the PP interval was prolonged to $700 \mathrm{msec}$. Thereafter a transient period of 'complete' atrioventricular block occurred from the end of Fig. 2 to the last beat in Fig. 3. During this period the PP intervals were still longer than control. His bundle recordings showed that the atrial (A) impulses (and of course the $\mathbf{P}$ waves) were not followed by $\mathrm{H}$ deflections. Hence, the block occurred between the atria and the site, within the His bundle, from which the $\mathrm{H}$ deflection was recorded.

During the period of atrioventricular block the 

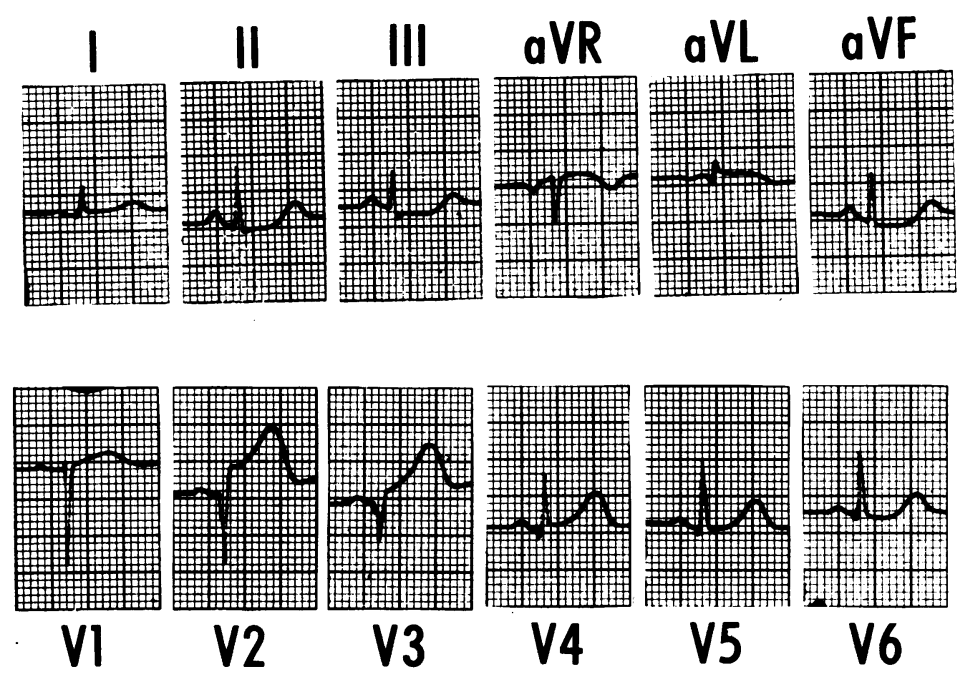

FIG. I (Case I) Twelve lead electrocardiogram showing sinus rhythm, narrow $Q R S$ complexes, and recent anteroseptal myocardial infarction.

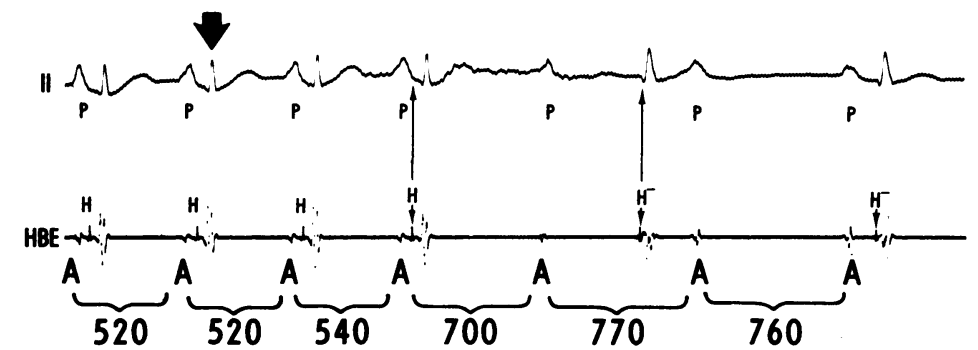

FIG. 2 (Case I) His bundle recordings showing paroxysmal atrioventricular block appearing during sinoatrial slowing. The first blocked $P$ wave was preceded by $P R$ intervals of constant (normal) duration. Onset of carotid sinus massage is indicated by vertical arrow pointing downward. The conduction disturbance occurred between the low right atrial $(A)$ deflection and the site from which the $H i s(H)$ bundle electrogram was recorded. The last two ventricular complexes were slightly wider than the first four. The retrograde $H$ deflection appeared 5 msec after onset of QRS. In this Fig. as well as in Fig. 3 and 5 paper speed was 100 msec. HBE=bipolar electrogram recorded from the His bundle area. All values are expressed in msec.

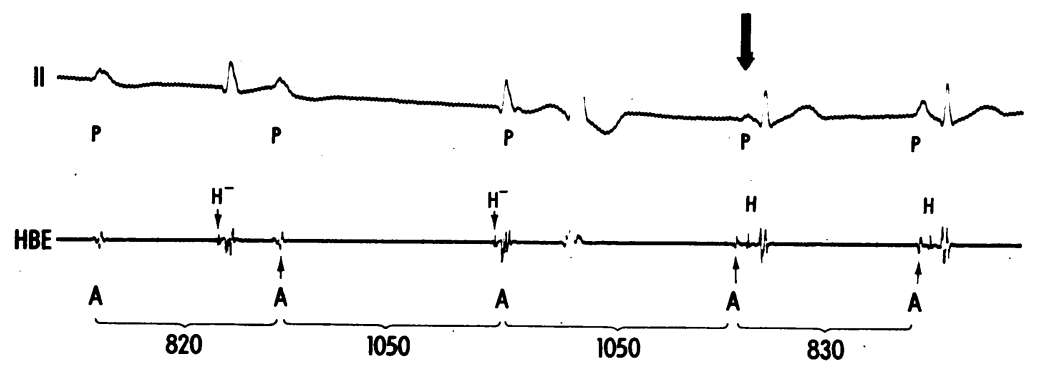

FIG. 3 (Case I) Termination of carotid sinus massage (vertical arrow) followed by a return to sinus rhythm (last beat). 
ventricular rhythm originated below the so-called bifurcation of the His bundle (in the bundle-branches or in the divisions of the left branch). This assumption was supported by the slightly more deformed and somewhat wider (90 msec) QRS complexes and by (retrograde) activation of the His bundle $5 \mathrm{msec}$ after that of the ventricles ( $\mathrm{VH}$ interval of $5 \mathrm{msec}$ ). A His bundle rhythm was excluded, since the QRS morphology and $\mathrm{HV}$ intervals would have been similar to those of control beats (Castellanos et al., 1972).

In Fig. 3, the third (wide) QRS complex was a ventricular extrasystole. Retrograde activation of the affected areas probably terminated the episode of paroxysmal atrioventricular block, since the fourth ventricular complex, preceded by a $\mathbf{P}$ wave of abnormal configuration, was conducted from the atria with a short PR interval (ectopic atrial rhythm ?). Finally, the last beat had the same atrioventricular conduction intervals and QRS configuration as the first two beats in Fig. 2 (which served as control).

To summarize, in this patient with narrow QRS complexes, paroxysmal atrioventricular block occurred when the rate was slowed by carotid sinus massage. The con- duction defect occurred between the atria and the site from which the His bundle deflection was recorded. Spontaneous atrioventricular block was not seen in this case.

\section{Case 2}

The tracings depicted in Fig. 4 and 5 were obtained from a patient with recent myocardial infarction. The top strip in Fig. 4 (day I) shows acute inferior wall 'injury', possible incomplete left bundle-branch block, and abnormal left axis deviation probably caused by left anterior hemiblock. In the bottom strip (day 3), the inferior infarction had evolved and the initial $r$ waves in leads II, III, and aVF had become smaller. The QRS complexes measured Iro msec. His bundle electrograms were recorded on the fourth post-infarction day (Fig. 5) when a catheter electrode was used because of sinus bradycardia (associated with first-degree atrioventricular block) not responding to drugs. The control atrioventricular conduction intervals (first QRS complex) had the following values: PA: $40 \mathrm{msec}$; AH: 95

FIG. 5 (Case 2) His bundle recordings showing paroxysmal atrioventricular block appearing during sinoatrial slowing. The first blocked $P$ wave was preceded by $P R$ intervals of constant (prolonged) duration. Onset of carotid sinus massage is at the start of the figure. In this case the conduction delay and block occurred between the site from which the His bundle electrogram was recorded and the ventricles. 
msec; and HV: ro5 msec. Since the QRS complexes only measured I IO msec, the prolongation of the HV interval (upper limit of normal: $55 \mathrm{msec}$ ) was attributed to a conduction delay within the $\mathrm{His}$ bundle itself, below the site from which the $\mathrm{H}$ deflection was recorded.

During carotid sinus massage, started at the beginning of the Fig., the atrioventricular conduction intervals remained unchanged until the fourth $P$ wave failed to reach the ventricle after activating the $\mathrm{His}$ bundle. This $\mathbf{P}$ wave was blocked when the PP interval was increased (from a control value of $870 \mathrm{msec}$ ) to 905 msec.

Thereafter the fifth $P$ wave was also blocked. It is not known if the last $\mathbf{P}$ wave really activated the ventricles (with a longer-than-control HV interval), since the electrocardiographic recorder was stopped after inscription of the corresponding $T$ wave and started a few seconds later when the atrioventricular conduction intervals had attained their control values. An alternative, though less likely, explanation is that the last QRS complex originated in the 'low' $\mathrm{His}$ bundle, the $\mathrm{H}$ deflection not being recorded for technical reasons. Spontaneous second-degree or advanced atrioventricular block did not occur.

To summarize, in this patient without abnormally wide QRS complexes (but with prolonged HV intervals), paroxysmal atrioventricular block appeared when the atrial rate was slowed by carotid sinus massage. The conduction defect occurred between the site from which the His bundle deflection was recorded and the ordinary ventricular myocardium. Spontaneous atrioventricular block was not seen in this case.

\section{Discussion}

Electrocardiographic criteria for paroxysmal atrioventricular block and its relation with type II (Mobitz) second-degree atrioventricular block

In 1973, Rosenbaum and co-workers reviewed 18 cases ( 8 of their own and Io from other authors) of paroxysmal atrioventricular block initiated by sinoatrial slowing in which atrioventricular conduction was resumed after an escape beat. Wide QRS complexes were seen in all cases except one. In most, if not all, of the tracings, the PR interval preceding the first non-conducted $P$ wave had a constant duration. Type II(Mobitz) atrioventricular block is also usually characterized by its association with wide QRS complexes and by the fact that the first blocked $P$ wave is not preceded by PR intervals of varying duration. However, classical type II (Mobitz) block need not be triggered by a decrease in atrial rate (Mobitz, 1924).

From the viewpoint of the surface electrocardiogram, the form of paroxysmal atrioventricular block occurring in the two patients described in the present report can be considered as a variant of type II (Mobitz) atrioventricular block since the PR intervals preceding the first blocked $P$ wave had a constant duration. This form of type II (Mobitz) block was initiated by sinoatrial slowing. In Case I it was terminated by a ventricular extrasystole. It should be stated that we have used the term type II (Mobitz) atrioventricular block in a descriptive (surface electrocardiographic) sense, being well aware that it can result from different mechanisms.

\section{Site where conduction disturbance occurs in paroxysmal atrioventricular block}

Although His bundle electrograms were not recorded, Rosenbaum et al. (1973) postulated that in I 7 of the 18 cases they studied the conduction disturbance occurred below the bifurcation of the His bundle. In the remaining case, the His bundle itself was probably involved. Testoni et al. (1973) analysed the tracings of II patients. The affected region was believed to have been what they called the 'specific system' (presumably the infra-atrioventricular nodal specialized conducting system). In a case reported by Coumel et al. (197I) His bundle recordings showed that the block occurred within the His bundle or left bundle-branch.

Our two patients with acute myocardial infarction had paroxysmal atrioventricular block only during carotid sinus massage. In Case 2 (with a left anterior hemiblock and an inferior wall myocardial infarction) the block most probably involved an area of the His bundle located below the site from which the $\mathrm{H}$ deflection was recorded, therefore being similar to Case 17 of Puech et al. (197I), (reproduced as Fig. 77 of the textbook by Puech and Grolleau (1972)).

Case I resembled Case 4 of Rosen et al. (I97I) in that the atrioventricular block (induced by carotid sinus massage) occurred at the 'AH level'. It should be stressed that, as mentioned by Puech and Grolleau (1972), Langendorf, Cohen, and Gozo (1972), and Narula (I973), block at the AH level need not always be located at the atrioventricular node, since the conduction defect can occur at the 'upper' His bundle, above the site from which the $\mathrm{H}$ deflection is recorded. Moreover, a 'split' $\mathrm{H}$ deflection might be present and the position of the catheter (in reference to the His bundle) can be such that only the distal deflection is recorded (Narula, 1973).

That the atrioventricular block in which the nonconducted $\mathbf{P}$ wave is preceded by constant $\mathbf{P R}$ intervals almost invariably occurs below the node further supports an infra-atrioventricular nodal origin for Case I. Nevertheless, this assumption could not be proven, and based on the actual data 
obtained the block could have occurred at either atrioventricular node or 'upper' His bundle.

\section{Mechanism of paroxysmal atrioventricular block}

According to Langendorf (1973), the mechanism postulated for the specific variety of paroxysmal atrioventricular block discussed by Rosenbaum et al. (1973) cannot be responsible for all, or even the majority of cases of type II Mobitz atrioventricular block.

Rosenbaum et al. (1973) believed that paroxysmal atrioventricular block precipitated by atrial slowing was related to 'hypopolarization plus spontaneous diastolic depolarization' (phase 4 block), when terminated by an escape beat, and to repetitive concealed conduction when atrioventricular conduction was re-established without an intervening ectopic beat. Coumel et al. (1971) described a case (proven by His bundle recordings) of paroxysmal, bradycardia-dependent, phase 4 block exposed by premature atrial beats. These authors did not attribute this conduction disturbance to a vagalinduced depression of conductivity. The vagal effects were thought to be indirect, that is, only related to the atrial slowing per se, which gave enough time (when the PP interval was decreased to a 'critical' level) for the atrial impulse to appear late in the cycle, on the phase 4 block range.

Explanations can be postulated in the two cases presented in this communication. For instance, the block could have been due to a vagal-related depression of conduction, which in Case I occurred at the atrioventricular node, or 'upper' His bundle, and in Case 2 at the 'low' His bundle. Against this assumption are long held views implying that the vagus does not significantly affect conduction within the ventricular specialized tissues. Nevertheless, Puech and Grolleau (1972) have observed that carotid sinus massage prolongs the AH interval (Fig. 67 and 76) in some cases and the HV interval in others (Fig. 77).

On the other hand, it is also possible that, in our two cases the atrioventricular block (induced by sinoatrial slowing) was a 'phase 4 block' related to diastolic depolarization occurring in the 'upper' His bundle (Case $\mathrm{I}$ ) and at the low His bundle (Case 2). Finally, two separate mechanisms might have been operating, namely, vagal-related atrioventricular nodal block in Case $I$ and 'intra' His bundle phase 4 block in Case 2.

We hope that this preliminary report can stimulate further studies which can lead to a better understanding of the genesis of Type II Mobitz atrioventricular block.

\section{References}

Castellanos, A., Jr., O’Brien, H., Castillo, C. A., Myerburg, R. J., and Beffler, B. (1972). Contribution of His bundle recordings to analysis of abnormal beats with right bundle branch block-superior axis pattern. British Heart fournal, 34, 795 .

Castillo, C. A., and Castellanos, A., Jr. (197r). Retrograde activation of the His bundle in the human heart. American fournal of Cardiology, 27, 264.

Coumel, P., Fabiato, A., Waynberger, M., Motte, G., Slama, R., and Bouvrain, I. (197I). Bradycardia-dependent atrio-ventricular block. Report of two cases of A-V block elicited by premature beats. Fournal of Electrocardiology, 4, 168.

Jensen, G., Sigurd, B., Meibom, J., and Sandøe, E. (1973). Adams-Stokes syndrome caused by paroxysmal thirddegree atrioventricular block. British Heart fournal, 35, 516.

Langendorf, R. (1973). The role of spontaneous diastolic depolarization in second degree $\mathrm{A}-\mathrm{V}$ block: the mechanisms of 'paroxysmal' A-V block and of a new form of pseudo-supernormal A-V conduction. Chest, 63, 652.

Langendorf, R., Cohen, H., and Gozo, E. G., Jr. (1972). Observations on second degree atrioventricular block, including new criteria for the differential diagnosis between Type I and Type II block. American fournal of Cardiology, 29, III.

Mobitz, W. (1924). UUber die unvollständige Störung der Erregungsüberleitung zwischen Vorhof und Kammer des menschlichen Herzens. Zeitschrift für die gesamte experimentelle Medizin, 41, 180.

Narula, O. (1973). Conduction disorders in the A-V transmission system. In Cardiac Arrhythmias, p. 263. Ed. by L. S. Dreifus and W. Likoff. Grune and Stratton, New York.

Puech, P., and Grolleau, R. (1972). L'Activité du Faisceau de His Normale et Pathologique. Editions Sandoz, Paris.

Puech, P., Grolleau-Raoux, R., Latour, H., Cabasson, J., Robin, J. M., Baissus, C., and Gilbert, M. (1971). Diagnostic des blocs tronculaires hisiens par l'enregistrement endocavitaire et la stimulation du faisceau de His. Archives des Maladies du Coeur et des Vaisseaux, 63, 315.

Rosen, K. M., Loeb, H. S., Gunnar, R. M., and Rahimtoola, S. H. (197I). Mobitz Type II block without bundlebranch block. Circulation, 44, 1111 .

Rosenbaum, M. B., Elizari, M. V., Levi, R. J., and Nau, G. J. (1973). Paroxysmal atrioventricular block related to hypopolarization and spontaneous diastolic depolarization. Chest, 63, 678.

Sachs, A., and Traynor, R. L. (1933). Paroxysmal complete auriculoventricular heart-block. American Heart fournal, 9, 267.

Slama, R., Coumel, P., Motte, G., Fanjoux, J., Auperrin, A., and Penther, P. (1969). Etude électrocardiographique de l'installation et de la disparition du trouble de conduction dans deux cas de bloc auriculo-ventriculaire paroxystique. Archives des Maladies du Coeur et des Vaisseaux, 62, 101.

Testoni, F., Montemurro, G., and Tommaselli, A. (1973). Concealed conduction as a mechanism of cardiac arrest in atrioventricular partial block. International Research Communications System: Medical Science. Abstract (73-3) I I-10-1. (Cited in inset to fournal of International Research Communication, 1 , No. I, P. IV.)

Requests for reprints to Dr. Agustin Castellanos, University of Miami School of Medicine, P.O. Box 520875, Biscayne Annex, Miami, Florida 33152, U.S.A. 